\title{
A percepção de internautas sobre as receitas mais acessadas em mídia digital
}

\author{
Internet users' perception of the most accessed recipes in digital media \\ Percepción de los internautas sobre las recetas más visitadas en medios digitales
}

Recebido: 10/09/2021 | Revisado: 15/09/2021 | Aceito: 25/09/2021 | Publicado: 27/09/2021

\author{
Ana Carolina Silva da Costa \\ ORCID: https://orcid.org/0000-0002-6130-6789 \\ Centro Universitário UNA, Brasil \\ E-mail: anacarolinasdc@hotmail.com \\ Maria Marta Amancio Amorim \\ ORCID: https://orcid.org/0000-0001-8268-2508 \\ Universidade Aberta de Lisboa, Portugal \\ E-mail: martamorim@hotmail.com
}

\begin{abstract}
Resumo
O objetivo desse estudo é analisar a percepção dos internautas sobre as receitas mais acessadas em veículo de mídia gastronômica na perspectiva da alimentação e nutrição. Estudo quantitativo e qualitativo de um recorte do conteúdo de mídia digital referente à gastronomia e veiculado na internet, na página YouTube ${ }^{\circledR}$. Selecionou-se o canal Panelinha ${ }^{\circledR}$, dedicado à divulgação de receitas e vídeos culinários relacionados à alimentação. Os comentários de dois vídeos com maior número de visualizações pelos internautas foram transcritos, categorizados e interpretados pela análise de conteúdo. As postagens mais visualizadas foram "Como fazer a omelete perfeita - cremosa, fofinha... hmmm!", com 1 milhão de acessos e "Em uma panela só: Risoto da Rita Lobo com 453 mil visualizações. As categorias levantadas foram: feedback positivo, elogio à receita, elogio à apresentadora/canal, feedback negativo, dúvidas, sugestões, críticas. No vídeo "Como fazer a omelete perfeita" analisaram-se 235 postagens, $38 \%$ realizadas por mulheres e $55 \%$ por homens e $7 \%$ sem identificação do sexo. Vídeo de menor tempo de duração, menor quantidade de ingredientes e maior simplicidade nas técnicas aplicadas, associadas ao apelo saudável alcançou maior número de internautas. O vídeo mais longo, "Em uma panela só: risoto da Rita Lobo", com 91 comentários, 71\% realizados por mulheres, $26 \%$ por homens e $3 \%$ sem identificação do sexo. Vídeo com mais ingredientes e preparos despertou maior interesse no público feminino, porém, suscitou mais dúvidas. Esses vídeos foram capazes de distribuir as opiniões mais positivas dos usuários, que atuaram como agentes incentivadores para a prática da alimentação saudável exibida.
\end{abstract}

Palavras-chave: Culinária; Dieta; Ciências da nutrição; Internet.

\begin{abstract}
The aim of this study is to analyze the perception of internet users about the most accessed recipes in gastronomic media from the perspective of food and nutrition. Quantitative and qualitative study of a clipping of digital media content related to gastronomy and published on the internet, on the YouTube ${ }^{\circledR}$ page. The Panelinha ${ }^{\circledR}$ channel was selected, dedicated to the dissemination of recipes and culinary videos related to food. The comments of two videos with the highest number of views by internet users were transcribed, categorized and interpreted by content analysis. The most viewed posts were "How to make the perfect omelet - creamy, fluffy... hmmm!", with 1 million hits and "In one pot: Risotto by Rita Lobo with 453 thousand views. The categories raised were: positive feedback, praise to the recipe, praise to the presenter/channel, negative feedback, doubts, suggestions, criticisms. In the video "How to make the perfect omelet" 235 posts were analyzed, $38 \%$ made by women and $55 \%$ by men and $7 \%$ without gender identification. Video with shorter duration, fewer ingredients and greater simplicity in applied techniques, associated with a healthy appeal, reached a greater number of Internet users. The longest video, "In a pot: Rita Lobo's risotto", with 91 comments, $71 \%$ made by women, $26 \%$ by men and $3 \%$ without gender identification. Video with a recipe with more ingredients and preparations, aroused greater interest in the female audience, however, raised more doubts. These videos were able to distribute the most positive opinions of users, who acted as encouraging agents for the practice of healthy eating shown.
\end{abstract}

Keywords: Cooking; Diet; Nutrition sciences; Internet.

\section{Resumen}

El objetivo de este estudio es analizar la percepción de los internautas sobre las recetas más visitadas en los medios gastronómicos desde la perspectiva de la alimentación y la nutrición. Estudio cuantitativo y cualitativo de un recorte de contenido de medios digitales relacionados con la gastronomía y publicado en Internet, en la página de YouTube®. Se seleccionó el canal Panelinha ${ }^{\circledR}$, dedicado a la difusión de recetas y videos de cocina relacionados con la comida. Los comentarios de dos videos con mayor número de visualizaciones por parte de internautas fueron transcritos, categorizados e interpretados mediante análisis de contenido. Las publicaciones más vistas fueron "Cómo hacer la 
tortilla perfecta - cremosa, esponjosa ... hmmm!”, Con 1 millón de visitas y "En una olla: Risotto de Rita Lobo con 453 mil visitas. Las categorías planteadas fueron: feedback positivo, elogio a la receta, elogio al presentador / canal, feedback negativo, dudas, sugerencias, críticas. En el video "Cómo hacer la tortilla perfecta" se analizaron 235 publicaciones, $38 \%$ hechas por mujeres y $55 \%$ por hombres y $7 \%$ sin identificación de género. Los videos de menor duración, menos ingredientes y mayor sencillez en las técnicas aplicadas, asociados a un atractivo saludable, llegaron a un mayor número de internautas. El video más largo, "En una olla: el risotto de Rita Lobo", con 91 comentarios, $71 \%$ de mujeres, $26 \%$ de hombres y $3 \%$ sin identificación de género. El video con una receta con más ingredientes y preparaciones, despertó mayor interés en el público femenino, sin embargo, generó más dudas. Estos videos lograron difundir las opiniones más positivas de los usuarios, quienes actuaron como agentes alentadores para la práctica de una alimentación saludable mostrada.

Palabras clave: Cocinar; Dieta; Ciencias de la nutrición; Internet.

\section{Introduçãa}

As receitas culinárias foram transmitidas pela televisão desde a sua criação, primeiramente com o objetivo de divulgar a aplicabilidade dos utensílios e aparelhos eletrodomésticos. Mais tarde essas veiculações midiáticas passaram a atribuir maior destaque para o preparo da receita até dar origem aos programas de culinária como são conhecidos atualmente (Oliveira, 2016).

Os produtos midiáticos com o tema culinária e alimentação nas mais distintas formas aumentaram no Brasil nos últimos anos. Embora a cozinha tenha sido o último setor da sociedade de consumo a ser contaminado pelas mídias, fala-se também de revistas, livros, cadernos de gastronomia, blogs, programas televisivos com chefes celebridades e sítios eletrônicos e outros meios que se dedicam aos conteúdos voltados à alimentação, em diferentes perspectivas (Demozzi, 2014).

A mídia gastronômica ou food media - termo em língua inglesa para designar o mesmo movimento - pauta a convergência entre comida, entretenimento e gosto, de modo que a influência da mídia da comida vai além do divertimento, altera a maneira como as pessoas se relacionam com o alimento e alimentação (Jenkins, 2009).

A sociedade é influenciada pelo consumo de comidas associado ao ganho de status (Demozzi, 2014). O cenário de serviços e interações humanas de restaurantes no país por meio de comentários de usuários em plataforma da internet é citada como capaz de desempenhar importante papel na distribuição de opiniões de consumidores em sites, blog e fóruns (Cechinel \& Santos, 2018). Ribeiro, Marques e Filho (2016) afirmam que a intensa midiatização da gastronomia pode ser um indicativo de novos modos alimentares.

A alimentação, entendida sob a perspectiva social e cultural, envolve aspectos que vão além do caráter nutricional ou biológico do alimento. Nos primórdios da civilização, por exemplo, ao "criar" a própria comida o homem estava encontrando formas de garantir a sua subsistência e de seus pares a partir do manejo de tecnologias que permitiam a produção e conservação dos alimentos. Por outro lado, na contemporaneidade, a ideia de criar o próprio alimento pode ser revista segundo a perspectiva que enaltece as qualidades do criar, do cozinhar, do transformar, especialmente no contexto urbano (Demozzi \& Gruner, 2013).

Segundo o Guia Alimentar brasileiro a alimentação adequada e saudável é um direito humano básico que envolve

“a garantia ao acesso permanente e regular, de forma socialmente justa, a uma prática alimentar adequada aos aspectos biológicos e sociais do indivíduo e que deve estar em acordo com as necessidades alimentares especiais; ser referenciada pela cultura alimentar e pelas dimensões de gênero, raça e etnia; acessível do ponto de vista físico e financeiro; harmônica em quantidade e qualidade, atendendo aos princípios da variedade, equilíbrio, moderação e prazer; e baseada em práticas produtivas adequadas e sustentáveis. Ele está inserido num escopo de ações do governo brasileiro para a promoção da saúde e da segurança alimentar e nutricional. Nele encontram-se recomendações gerais sobre a escolha de alimentos, orientações sobre como combinar alimentos na forma de refeições, orientações sobre o ato de comer e a comensalidade e ainda fatores que podem ser obstáculos para a adesão das pessoas às recomendações do guia” (Brasil, 2014., p.). 
As mudanças sociais em relação ao comportamento alimentar das pessoas são cada vez mais influenciados e conectados aos conteúdos da mídia gastronômica, proporcionando à disposição da sociedade uma quantidade expressiva de informações sobre diferentes fenômenos, logo, são criadas e recriadas diferentes realidades (Seager, Chisleni, \& Botoluzzi, 2021). A midiatização da gastronomia está mudando a relação dos homens com os alimentos e os profissionais não podem ignorá-la. Assim é necessário discutir sobre como a ascensão da influência midiática na atualidade está impactando a alimentação das pessoas (Linares \& Trindade, 2011).

Assim o objetivo do presente trabalho é analisar a percepção dos internautas sobre as receitas mais acessadas em veículo de mídia gastronômica na perspectiva da alimentação e nutrição.

\section{Metodologia}

Trata-se de um estudo quantitativo e qualitativo de um recorte do conteúdo de mídia digital referente à gastronomia e veiculado na internet, na página YouTube ${ }^{\circledR}$. Selecionou-se o Panelinha ${ }^{\circledR}$ por ser um canal exclusivamente dedicado à divulgação de receitas culinárias e vídeos relacionados à temática alimentação.

O canal Panelinha ${ }^{\circledR}$ foi criado em 26 de maio de 2008 pela chef de cozinha e escritora Rita Lobo. Desde os anos 2000, produtos da mesma marca do canal já veicularam em outras mídias, como site, livros e produção em canal fechado de televisão. Os livros de Rita Lobo publicados de 2012 a 2018 possuem uma variedade de dicas relacionadas à saúde devido a sua parceria, em 2016, com o Núcleo de Pesquisas Epidemiológicas em Nutrição e Saúde da Faculdade de Saúde Pública da Universidade de São Paulo, responsável pela elaboração da versão atual do guia alimentar (Cordeiro, Fonseca, \& Ribeiro, 2020).

No YouTube ${ }^{\circledast}$, atualmente, a página possui 281 mil inscritos e 13 milhões de visualizações. Dentre os conteúdos, além da postagem de gravações que demonstram o passo a passo de diversas preparações, há também vídeos sobre técnicas culinárias e um minicurso sobre "comida de verdade" e alimentação saudável. Os vídeos postados são agrupados em playlists, de acordo com o conteúdo que exibem. Alguns dos temas destas listas são: técnicas culinárias, cortes, métodos de cocção e combinações de sabor, receitas para o dia-a-dia e receitas clássicas da gastronomia, comida infantil e dúvidas de seguidores.

Os dois vídeos do canal Panelinha ${ }^{\circledR}$ com o maior número de visualizações foram analisados quanto às receitas e aos comentários os internautas e alguns da apresentadora. As receitas foram analisadas quanto aos ingredientes e as técnicas culinárias utilizando como referencial teórico livros de gastronomia e os guias alimentares do Ministério da Saúde (Brasil, 2008; Brasil 2014).

Os comentários postados pelos internautas, segundo o gênero, foram transcritos e interpretados utilizando a técnica de análise de conteúdo segundo a perspectiva de Laurence Bardin, que designou o termo como um:

"conjunto de técnicas de análise das comunicações visando a obter, por procedimentos sistemáticos e objetivos de descrição do conteúdo das mensagens, indicadores (quantitativos ou não) que permitam a inferência de conhecimentos relativos às condições de produção/recepção (variáveis inferidas) destas mensagens” (Bardin, 2011, p. 47).

Para tanto, as três fases fundamentais: pré-análise, exploração do material (codificação) e tratamento dos resultados inferência e interpretação foram seguidas. Na pré-análise, os comentários dos usuários nos dois vídeos com maior número de acessos no canal Panelinha ${ }^{\circledR}$ do YouTube $^{\circledR}$ foram compilados e constituíram o corpus da pesquisa. Na exploração do material os dados brutos foram categorizados, de modo que os temas/comentários que se repetiam com maior frequência foram destacados em unidades comparáveis, com vistas a codificação para o registro de dados e posterior análise temática. Por fim, na fase de tratamento dos resultados - inferência e interpretação, foi realizada uma interpretação dos dados brutos 
categorizados para além do conteúdo manifestado nas páginas da web, ou seja, em busca do conteúdo latente, foi inferido o sentido por trás das frases imediatamente escritas (Bardin, 2011).

\section{Resultados e Discussão}

O Panelinha ${ }^{\circledR}$ é um canal do YouTube ${ }^{\circledR}$ que alcança um número grande de internautas. Os usuários que acompanham os vídeos realizados pela chef Rita Lobo recebem informações a respeito de práticas que valorizam a alimentação saudável e adequada. As postagens são objetivas: em poucos minutos captam a atenção do internauta e procuram promover a alimentação saudável.

De acordo com a popularidade, as postagens mais visualizadas foram "Como fazer a omelete perfeita - cremosa, fofinha... hmmm!" (Panelinha $\left.{ }^{\circledR}, 2010\right)$, pertencente à playlist "Dicas que funcionam”, com 1 milhão de acessos; e "Em uma panela só: Risoto da Rita Lobo" (Panelinha $\left.{ }^{\circledR}, 2014\right)$, da lista "Em uma panela só”, com 453 mil visualizações.

$\mathrm{Na}$ categorização dos discursos dos dois vídeos, os comentários dos usuários foram agrupados em sete categorias principais, a saber: 1. Feedback positivo, 2. Elogio à receita, 3. Elogio à apresentadora/ao canal, 4. Feedback negativo, 5. Dúvidas, 6. Sugestões, 7. Críticas.

Os discursos das categorias mais relevantes nos dois vídeos serão apresentados em seguida, bem como a análise da receita.

\subsection{Video "Como fazer a omelete perfeita - cremosa, fofinha... hmmm!"}

Esta postagem teve duração de três minutos e nove segundos, foi acessada 1 milhão de vezes, com 253 comentários postados. Na preparação, cujo rendimento informado servia duas pessoas, foram utilizados seis ovos, seis colheres de sopa de leite, sal e pimenta do reino a gosto e manteiga suficiente para untar a frigideira. Além de rodelas de tomate e folhas de manjericão como acompanhamento (Panelinha $\left.{ }^{\circledR}, 2010\right)$.

Os ovos foram quebrados em um recipiente, onde foi acrescentado o leite. Os dois ingredientes foram mexidos rapidamente, sem que houvesse incorporação de ar. Esta mistura foi então transferida para uma frigideira antiaderente aquecida e untada com manteiga. À medida que os ovos foram se solidificando nas extremidades da frigideira, com auxílio de uma espátula, a mistura foi sendo puxada no sentido das laterais para o centro. Esta técnica é a responsável por proporcionar umidade e maciez na receita. Somente quando a omelete se tornou mais consistente, o movimento de mistura foi interrompido, sendo então adicionado o sal e a pimenta do reino, sem acréscimo de outros recheios. Para finalizar, a omelete foi solta do fundo da frigideira e virada em três partes. Para servir, a receita foi dividida ao meio e transferida para dois pratos, onde foi acompanhada de seis rodelas de tomate e duas folhas de manjericão para cada pessoa (Panelinha ${ }^{\circledR}, 2010$ ).

O homem atua ativamente sobre os alimentos, transformando-o de acordo com os seus interesses, seja preparando um prato doce ou salgado. A omelete exemplifica a diversidade de alimentos que se pode preparar com o ovo (Jacob, 2013). As práticas de cozinha passaram por transições importantes na sociedade brasileira no que diz respeito à valorização desta atividade nos contextos do cotidiano e da cozinha como lazer e profissão (Demozzi, 2014).

Quanto aos comentários, da amostra de 253 postagens, 18 foram excluídos por se constituírem de respostas que foram inseridas dentro de comentários principais ou por terem sido postados em duplicata. Desta forma, para fins de análise, foram consideradas 235 postagens, sendo 90 (38\%) realizadas por usuários do sexo feminino, 128 (55\%) do masculino. Ao observar o nome do usuário e a foto do perfil na página da internet, não foi possível identificar o sexo dos mesmos em 17 comentários (7\%). (Panelinha $\left.{ }^{\circledR}, 2010\right)$.

Ao realizar a categorização obteve-se o resultado dos percentuais dos comentários descrito na Figura 1. O maior número de participantes relatou sucesso ao executar a receita (feedback positivo), em seguida vieram aqueles que postaram 
elogios à receita divulgada, e depois aqueles que elogiaram a apresentadora e a página. Uma pequena parte apresentou dúvidas quanto ao modo de preparo, aos ingredientes ou sobre como adquirir o livro da apresentadora. Outros tentaram, mas não conseguiram reproduzir a preparação (feedback negativo) e ainda houveram outros que postaram sugestões, e aqueles que fizeram críticas.

Figura 1. Categorias dos comentários, distribuídas em percentuais, do vídeo "Como fazer a omelete perfeita - cremosa, fofinha... Hmmm!” (Panelinha $\left.{ }^{\circledR}, 2010\right)$.

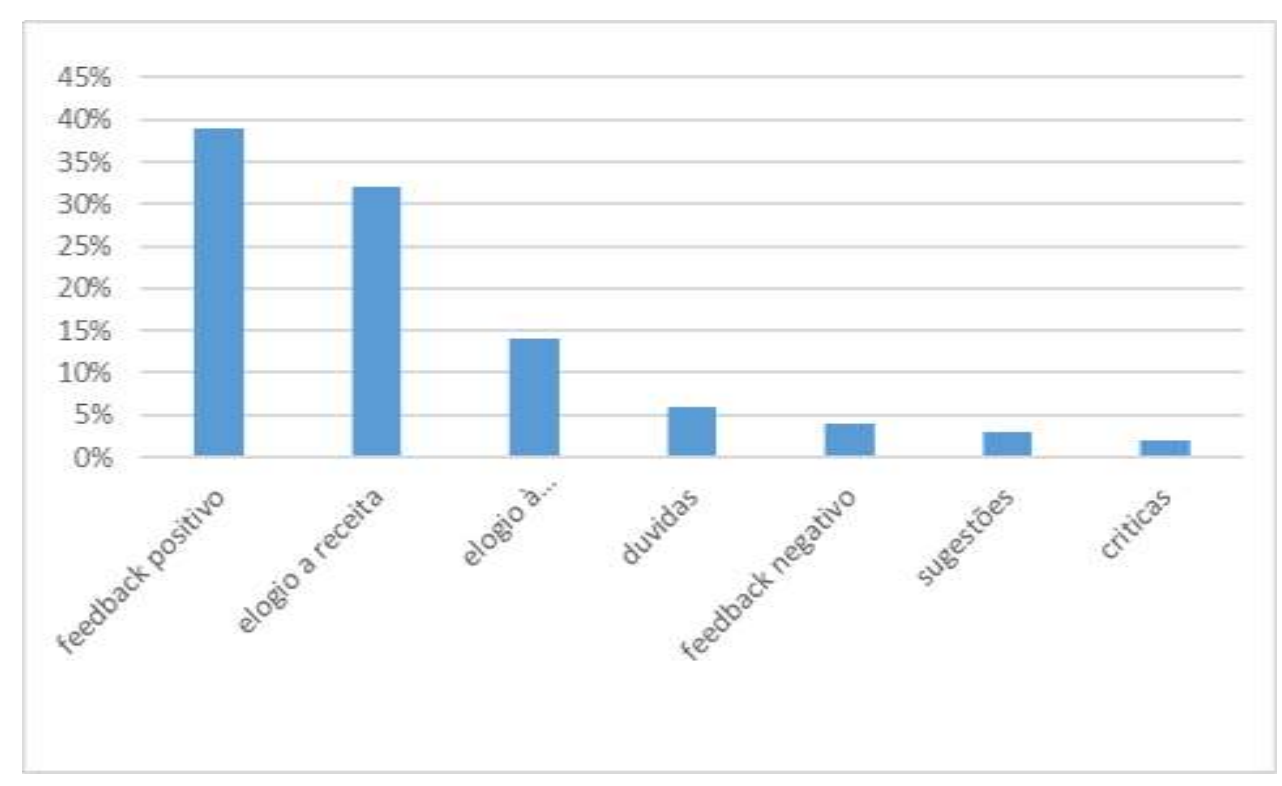

Fonte: Autores (2021).

Ao interpretar os comentários postados neste vídeo, nota-se uma incidência de maior número do público masculino. No Quadro 1 são apresentados os discursos masculinos para aqueles que relataram sucesso ao executar a receita (feedback positivo).

Quadro 1. Discursos da categoria Feedback positivo para o vídeo "Como fazer a omelete perfeita - cremosa, fofinha... hmmm!"

"Gostei muito fiz e ficou otimo"

"Perfeita! Fiz aqui e deu certinho! Obrigado, ganhou +1 inscrito"

"muito bom msm,to fazendo direto"

"aki em casa so tinha ovo valeu meu salvou kkkkkkkkkkkkkkkkkkk"

"Eu fiz e fico ótimo! Obrigado =)"

"Fiz a receita e ficou muito boa."

"Aew, deu certo, muito obrigado mesmo gostei e favorito pra vc"

"Sozinho em casa .. só tinha ovo .. procurei isso .. e me senti um mestre cuca!"

"Legal, eu fiz o teste hoje, e a minha filinha quase não deixou nada pra mim :-) Obrigado pela dica." 
Os feedbacks positivos em relação à receita - ótima, muito boa mesmo, favorita e legal podem estar associados ao fato da receita ser prática e de rápida execução. O sentimento de sentir "um mestre cuca" foi enaltecido por um usuário, pois a receita com poucos processos e ingredientes foi executada por ele, que não possui as habilidades de um cozinheiro. A presença do ovo, como ingrediente fácil de ser encontrado nas cozinhas foi destacada como elemento positivo.

A omelete resulta da combinação e preparo dos ingredientes descritos na receita e as maneiras de comer essa preparação constituem parte importante da cultura de uma sociedade, que está relacionada com a identidade e o sentimento de pertencimento social das pessoas, com a sensação de autonomia, com o prazer e o bem-estar propiciado ao comer esse prato (Brasil, 2014).

No Quadro 2 são apresentados os discursos daqueles homens que fizeram elogio à receita, que é simples, rápida e prática.

Quadro 3. Discursos da categoria Elogio à receita para o vídeo "Como fazer a omelete perfeita (cremosa, fofinha... hmmm!)"

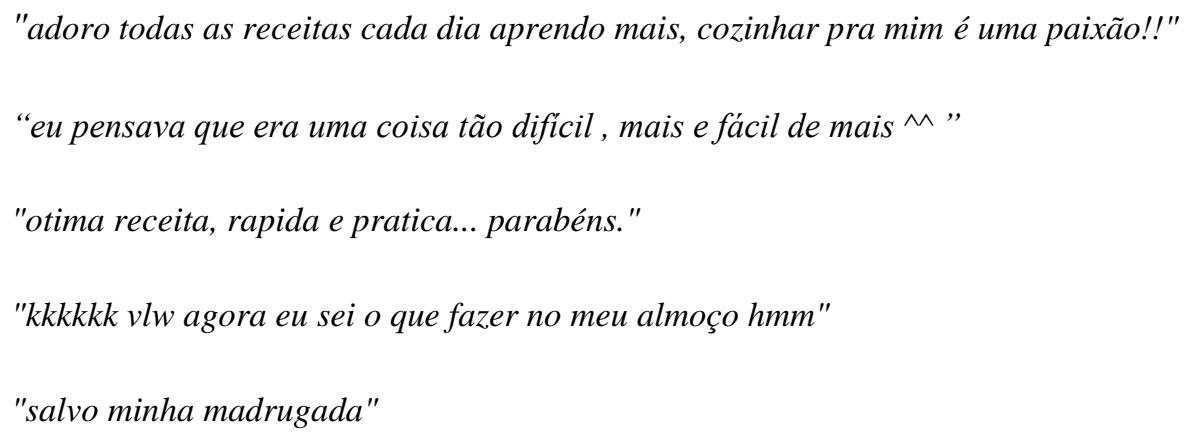

Fonte: Panelinha ${ }^{\circledR}(2010)$.

Os elogios dos homens pautaram do adoro ao gostoso, e do fácil ao simples. O fato de cozinhar para si mesmo se tornou uma paixão, seja no almoço, madrugada ou compartilhando a omelete com o filho. A prática de executar a receita tornase um aprendizado, dando liberdade e autonomia aos homens.

A autonomia é ressalta no Guia Alimentar

“o acesso a informações confiáveis sobre características e determinantes da alimentação adequada e saudável contribui para que pessoas, famílias e comunidades ampliem a autonomia para fazer escolhas alimentares e para que exijam o cumprimento do direito humano à alimentação adequada e saudável “(Brasil, 2014, p.21).

A chef Rita Lobo afirma durante demonstração do preparo da omelete: "Ovo é um ingrediente generoso. Ele faz doce, salgado e, principalmente, refeições rápidas, saudáveis e muito nutritivas” (Panelinha $\left.{ }^{\circledR}, 2010\right)$. Esse discurso foi capaz de informar benefícios do ovo que contêm proteínas de alto valor biológico e a metade de ácidos graxos insaturados e vitaminas do complexo B (Brasil, 2008).

A apresentadora não apenas executa as receitas, mas valoriza bons hábitos alimentares durante suas falas. É o que pode ser percebido nos discursos que enaltecem as qualidades dos ovos e a construção de sabores numa receita por meio de ervas e especiarias, em detrimento do uso de temperos industrializados. A ampliação da autonomia para fazer escolhas alimentares e cumprir o direito humano à alimentação adequada e saudável é conseguida pelo acesso a informações confiáveis (Brasil, 2014). 


\subsection{Vídeo “Em uma panela só: Risoto da Rita Lobo” (Panelinha", 2014)}

Em relação ao segundo vídeo mais acessado do canal Panelinha ${ }^{\circledR}$, com 10 minutos e 14 segundos de duração e 453 mil acessos, a apresentadora utilizou uma cenoura, que foi descascada e ralada, um talo de salsão cortado em pedaços pequenos, além de folhas deste mesmo talo, um alho poró cortado em rodelas e uma folha do mesmo inteira, além de uma cebola picada em cubos médios, arroz para risoto, finalizando com damasco, queijo e limão (Panelinha ${ }^{\circledR}, 2014$ )

Em uma panela pré-aquecida em fogo médio foram adicionadas três colheres de sopa de azeite. A cebola foi dourada no azeite e, na sequência, foram adicionados a cenoura e os talos do salsão e do alho poró. Neste momento, os ingredientes foram temperados com sal e pimenta do reino a gosto, uma pitada de cravo da índia em pó e duas folhas de louro. Foram então adicionadas três xícaras de arroz para risoto (cálculo de meia xícara por pessoa). Os ingredientes foram misturados por alguns minutos na panela, onde foi adicionada uma xícara de chá de vinho branco. A água para cozimento foi calculada de acordo com a proporção de três xícaras para cada xícara de arroz, neste caso, nove xícaras, equivalente ao total de 2,2 litros de água. Conforme a técnica proposta, 2/3 (1,5 litros) da água foi adicionada de uma só vez, para iniciar o cozimento (Panelinha ${ }^{\circledR}$, 2014).

Com os ingredientes imersos na água, foram adicionadas as folhas do salsão e do alho poró, inteiras e um pouco de tempero de sal e pimenta do reino. Enquanto o risoto cozinha, os demais ingredientes da receita são preparados: duas xícaras de damasco fatiados, duas xícaras de queijo meia cura ralado. Decorrido o tempo para a água do arroz começar a secar, foram retiradas as folhas de louro, salsão e alho poró e adicionado o restante da água $(700 \mathrm{~mL})$ aos poucos e sempre mexendo a mistura da panela, para proporcionar um risoto ao mesmo tempo cremoso e "ao dente", onde o grão está cozido, porém firme no interior. Após adicionada toda água, o fogo é desligado e acrescentado o damasco e o queijo. Para finalizar, adicionam-se raspas de dois limões e o caldo de um. Na montagem do prato, a preparação é ainda incrementada com um fio de azeite, uma pitada de pimenta do reino e algumas folhinhas de salsinha (Panelinha $\left.{ }^{\circledR}, 2014\right)$.

Rita Lobo compreende as necessidades do público e suas publicações são caracterizadas por trazer muitos detalhes na receita, permitindo que qualquer pessoa seja capaz de executá-la (Cordeiro, Fonseca \& Ribeiro, 2020).

$\mathrm{Na}$ receita do risoto foram usados alimentos in natura ou minimamente processados, em grande variedade e predominantemente de origem vegetal, base para uma alimentação nutricionalmente balanceada, saborosa, culturalmente apropriada e promotora de um sistema alimentar socialmente e ambientalmente sustentável (Brasil, 2014). Rita Lobo propõe o resgate do hábito de cozinhar com ingredientes mais naturais, ensinando desde as técnicas básicas de preparo de refeições para os iniciantes até aos mais experientes (Cordeiro, Fonseca \& Riberio, 2020).

No preparo do risoto deve-se preocupar com a qualidade higiênico-sanitária dos alimentos, como higienização e antissepsia das mãos, lavagem das frutas, legumes e verduras em água corrente e remolho em solução de hipoclorito de sódio; limpeza e desinfecção da cozinha (Brasil, 2014). Sugere-se que essas práticas sejam ensinadas pela apresentadora na demonstração da receita, para garantir a qualidade higiênico-sanitária da preparação.

Dos 110 comentários postados, 19 foram excluídos por se trataram de respostas inseridas dentro dos comentários principais ou por estarem em branco. Assim, foram analisadas 91 postagens, das quais 65 (71\%) foram feitas por mulheres, 24 (26\%) por homens e $2(3 \%)$ que não foram identificadas por sexo por insuficiência de informações no perfil do usuário (Panelinha $\left.{ }^{\circledR}, 2014\right)$.

Categorizando-se os comentários (Figura 2), notou-se que a metade dos usuários elogiou a receita, um quarto elogiou a apresentadora e o canal, alguns tiveram dúvidas quanto ao preparo ou ao uso de ingredientes, uma pequena parte relatou ter reproduzido com sucesso a preparação (feedback positivo), poucos fizeram sugestões e críticas, e somente alguns reproduziram a receita, porém sem sucesso (feedback negativo). 
Figura 2. Categorias distribuídas em percentuais dos comentários do vídeo "Em uma panela só: Risoto da Rita Lobo" (Panelinha $\left.{ }^{\circledR}, 2014\right)$.

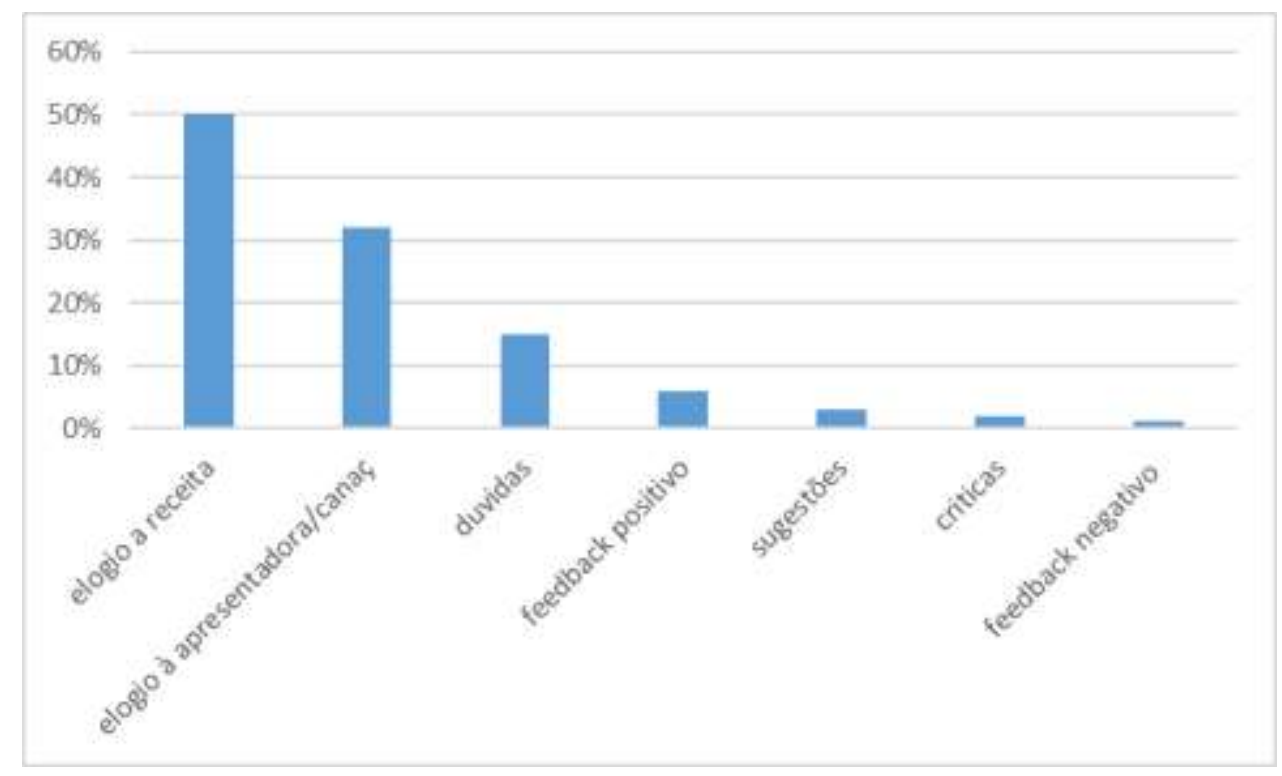

Fonte: Autores (2021).

Ao contrário do primeiro vídeo, a postagem sobre a preparação do risoto obteve a maioria dos comentários realizados por usuários do sexo feminino. Esta receita, no entanto, possui maior tempo de preparação - sete minutos e cinco segundos a mais e usa maior quantidade e variedade de elementos - oito a mais e necessita de mais etapas de preparo. Além disso, o episódio em questão constitui de uma aula, onde a apresentadora recebe cinco mulheres previamente definidas por meio de uma seleção do canal. Essas ocorrências podem ser responsáveis pelo vídeo ter despertado maior interesse no público feminino e são, inclusive, expressadas em um comentário realizado por usuário do sexo masculino, que critica: "Pô, só a mulherada, homem também cozinha!".

Outra constatação que pode ser inferida a partir dos comentários foi que, a maioria dos internautas que acompanhou a receita do risoto postou elogios à receita, elogios à apresentadora/canal e dúvidas. Nota-se então que, embora a receita seja enaltecida, os ingredientes e o preparo geraram muitas dúvidas e possivelmente poucas pessoas tentam reproduzi-la. A apresentadora, inclusive, antes do início da receita, adverte: "Vamos ao risoto, porque apesar de ele ser feito em uma panela só, a gente tem um monte de ingredientes para picar".

No Quadro 3, as falas dos internautas pertencentes à categoria "Dúvidas", são apresentadas. 
Quadro 4. Discursos de internautas da categoria Dúvidas no vídeo "Em uma panela só: Risoto da Rita Lobo"

"Ritaaa, amei o vídeo! Só me diz o que outros queijos poderia usar? Não acho o meia cura com facilidade... Bjs"

"Não tenho damasco. Vou tentar usar uvas passas e queijo parmesão. Será que fica bom?"

"Olá! Vocês tem alguma outra sugestão pro caldo além do salsão e alho poró? Aqui onde eu moro é muito difícil de encontrar esses ingredientes."

"e qual seria o arroz correto pro risotto?"

"Ola, grata pelo canal. Não foi colocado manteiga nessa receita, então não é tão necessário, né? E para fazer risto de camarão é só adicionar o camarao feito né?"

"Rita, pode colocar outros legumes?"

"Posso substituir o queijo por outros... e quais? ... Obrigada bjs"

Fonte: Panelinha ${ }^{\circledR}$ (2014).

As dúvidas em relação à substituição dos ingredientes como queijo, damasco, salsão, alho poró, arroz e vinho são colocadas pelas mulheres que assistiram ao vídeo.

Além da transformação pela culinária, o alimento passa a exercer outras funções simbólicas, como o arroz que se transformou em risoto, um prato completo (Jacob, 2013).

É importante mencionar sobre a apresentadora enfatiza a construção de sabor do prato por meio de "ingredientes de verdade", ervas e especiarias.

“Já podemos juntar os outros ingredientes aromáticos: a cenoura, o salsão, o alho poró. São os mesmos legumes que a gente usaria se estivesse fazendo um caldo caseiro. Este é o segredo para deixar esse risoto muito mais saudável. A gente faz comida de verdade e dispensa os temperos prontos” (Panelinha $\left.{ }^{\circledR}, 2014\right)$.

Estas afirmações reiteram a proposta do canal Panelinha ${ }^{\circledR}$ em divulgar o apelo saudável em todas as receitas executadas, estimulando os internautas a adotarem o mesmo estilo de vida e práticas alimentares.

Destaca-se ainda o método de preparação do risoto que, conforme a própria apresentadora deixa claro, trata-se de uma receita versátil, onde o risoto é preparado simultaneamente e - na mesma panela - onde o caldo está sendo elaborado:

"No método tradicional a gente vai colocando o caldo, assim, de concha em concha e mexendo bem até secar. Nesta técnica, a gente vai colocar $2 / 3$ do líquido ou da água de uma vez. É como se a gente tivesse fazendo um caldo de legumes enquanto cozinha o risoto. Isto vai deixar a gente mais livre pra continuar o preparo do risoto.” (Panelinha $\left.{ }^{\circledR}, 2014\right)$.

Segundo Wright e Treuille (1997) para se obter um risoto bem feito, com textura cremosa e perfeitamente cozido, o caldo deve ser acrescentado aos poucos, para que o arroz, embora sempre úmido, não fique imerso no líquido. Os cozinheiros não devem se afastar da panela enquanto o risoto está sendo feito, mexendo sempre no começo e, depois, enquanto cozinha, com menos frequência.

Por fim, outra diferença está na substituição da adição de gordura. Ao invés do tradicional uso da manteiga, é adicionado azeite de oliva, que confere à preparação, mais uma vez, um apelo mais saudável, seguindo a proposta do vídeo e 
do canal. O azeite contem maior teor de ácidos graxos insaturados em relação à manteiga, rica em ácidos graxos saturado (Brasil, 2008; Brasil, 2014)).

O Guia Alimentar brasileiro ressalta sobre o processo de transmissão de habilidades culinárias entre gerações e pontua que

"vem perdendo força e as pessoas mais jovens possuem cada vez menos confiança e autonomia para preparar alimentos. As razões para isso são complexas e envolvem a desvalorização do ato de preparar, combinar e cozinhar alimentos como prática cultural e social, a multiplicação das tarefas cotidianas e a incorporação da mulher no mercado formal de trabalho, além da oferta massiva e da publicidade agressiva dos alimentos ultraprocessados" (Brasil, 2014, p.112).

O consumo da alimentação adequada composta de alimentos in natura ou minimamente processados contempla desde a seleção, a aquisição, o pré-preparo, finalizando com o preparo, além da higienização da cozinha. Essas tarefas demandam tempo que a família deve dedicar ao preparo das refeições (Brasil, 2014).

\section{Considerações Finais}

A demonstração de receita culinária no vídeo "Como fazer a omelete perfeita (cremosa, fofinha... hmmm!)", com menor tempo de duração, menor quantidade de ingredientes e maior simplicidade nas técnicas aplicadas, associadas ao apelo saudável da refeição, alcançou maior número de internautas, dentre os quais se destacou a presença masculina nos feedbacks positivos realizados por meio de comentários postados na página da web. Já o vídeo mais longo, "Em uma panela só: Risoto da Rita Lobo", com receita composta por mais ingredientes e técnicas de preparo, despertou maior interesse no público feminino, porém, suscitou mais dúvidas.

Pode-se dizer que os comentários dos internautas postados nos dois vídeos analisados ressaltaram mais opiniões positivas do que negativas ao assistirem as gravações com a chef Rita Lobo. Acredita-se que a apresentadora Rita Lobo e os próprios internautas atuaram com agentes incentivadores para a prática da alimentação saudável e adequada exibida.

Uma das limitações do estudo foi não poder captar dados sobre a identidade dos internautas. Assim sugerem-se investigações com abordagens mais aprofundadas, realizadas por meio de questionários específicos, para conhecer maiores características desse público consumidor de mídia digital sobre gastronomia. A audiência em vídeos de receitas culinárias na internet fornece uma nova conjuntura para pesquisas e intervenções relacionadas a hábitos, não somente alimentares, mas também de âmbito nutricional, cultural e social.

\section{Referências}

Bardin, L. (2011). Análise de conteúdo. Edições 70.

Brasil. (2008). Guia alimentar para a população brasileira: promovendo a alimentação saudável, Ministério da Saúde. 2008. http://bvsms.saude.gov.br/bvs/publicacoes/guia_alimentar_populacao_brasileira_2008.pdf.

Brasil. (2014). Guia alimentar para a população brasileira: promovendo a alimentação saudável, (2a ed.), Ministério da Saúde. http://bvsms.saude.gov.br/bvs/publicacoes/guia_alimentar_populacao_brasileira_2ed.pdf.

Cechinel, E.; \& Santos, A. R. (2018). Comi, gostei e postei: Tripadvisor e experiências marcantes em restaurantes. Rosa dos Ventos: Turismo e Hospitalidade, 10(3), 538-557. http://dx.doi.org/10.18226/21789061.v10i3p538.

Cordeiro, E. P., Fonseca, L. R. \& Ribeiro, R. C. (2020). Evolução dos livros de culinária brasileiros e sua relação com o cozinhar na contemporaneidade. Demetra, 15, e47370. https://doi.org/demetra.2020.47370.

Demozzi, S. F., \& Gruner, C. (2013). A cozinha ornamental: a construção do gosto por meio das representações midiáticas. Dito Efeito: revista de comunicação da UTFPR, 4 (5), 1-15. https://periodicos.utfpr.edu.br/de/article/viewFile/2143/2004. 
Research, Society and Development, v. 10, n. 12, e455101220461, 2021

(CC BY 4.0) | ISSN 2525-3409 | DOI: http://dx.doi.org/10.33448/rsd-v10i12.20461

Demozzi, S. F. (2014). A cozinha em pauta: história, comunicação e sentimento nas práticas da cozinha do cotidiano e na cozinha como lazer (Dissertação de Mestrado). Universidade Federal do Paraná, Pós-Graduação em História, Setor de Ciências Humanas, Letras e Artes, Curitiba, https://acervodigital.ufpr.br/bitstream/handle/1884/35680/R\%20-\%20D\%20-\%20SABRINA\%20FERNANDA\%20DEMOZZI.pdf?sequence=1

Jacob, H. M. A. (2013). Gastronomia, culinária e média, Estudo dos ambientes midiáticos e das linguagens da comida e da cozinha. Tese Doutorado em Comunicação e Semiótica. Pontifícia Universidade Católica de São Paulo. https://sapientia.pucsp.br/bitstream/handle/449 7/1/Helena\%20Maria\%20Afonso\%20Jacob.pdf

Jenkis, H. (2009) Cultura da Convergência. Aleph.

Linares, N. L., \& Trindade, E. (2011). Processos de movimentos e significados simbólicos no consumo alimentar. Pensamento \& Realidade, 26 (2), $46-64$. https://revistas.pucsp.br/index.php/pensamentorealidade/article/view/7866/5752.

Oliveira, C. C. (2016). Das concepções e representações do gosto pela mídia: reflexões acerca da imagem estetizada da comida na divulgação de receitas culinárias. Cultura Midiática: Revista do Programa de Pós-Graduação em Comunicação da Universidade Federal da Paraíba, 9 (1), 136-150. http://www.periodicos.ufpb.br/index.php/cm/article/viewFile/29367/15681.

Panelinha $^{\circledast}$. (2010). Como fazer a omelete perfeita (cremosa, fofinha... hmmm!). https://www.youtube.com/watch?v=VsMrISDNW_8.

Panelinha $^{\circledR .}$ (2014). Em uma panela só: risoto da Rita Lobo. https://www.youtube.com/watch?v=EjjkSF-0kJ0.

Ribeiro, R. C., Marques, R. C.; \& Filho, E. G. J. F. (2016). A criatividade dos chefs de cozinha e o consumo moderno da gastronomia. Demetra: Alimentação, Nutrição \& Saúde, 11 (2), 265-274. https://doi.org/10.12957/demetra.2016.15443.

Seager, F. F., Chisleni, T. S, \& Botoluzzi, V. I. (2021). Educação a distância, mídia e indivíduo na sociedade pós-moderna: reflexões sobre educação e cultura mediatizada pelo consumo. Research, Society and Development, 10(1), e35110110165. http://dx.doi.org/10.33448/rsd-v10i1.10165

Wright, J.; \& Treuille, E. (1997). Todas as técnicas culinárias: Le Cordon Bleu. (2a ed.), E. Bottmann \& V. Caputo (Trad.). Marco Zero. 